\title{
El papel de los municipios en la expansión de la red de edificios escolares públicos en España, 1920-1937
}

\author{
(The role of municipalities in the expansion of the public school \\ building network in Spain, 1920-1937)
}

\author{
María del Pilar GARCÍA SALMERÓN \\ Colegio Público Fuente del Oro \\ Cuenca, España
}

\begin{abstract}
RESUMEN: El propósito de modernización y de universalización de la enseñanza primaria en España emprendido por el Estado a comienzos del siglo XX exigía la construcción de miles de edificios escolares. Hasta 1920 esta tarea era de competencia municipal, aunque la generalizada penuria de las arcas municipales no permitía la resolución del asunto. Durante la década de los años veinte y treinta del siglo pasado el Estado se involucró firmemente en la construcción de nuevas escuelas, aunque requirió la iniciativa y cooperación de los municipios. El análisis de las fórmulas de colaboración entre el Estado y los municipios españoles para conseguir el mayor incremento de edificios escolares logrado hasta entonces dentro del sistema educativo español constituye el contenido de este artículo.
\end{abstract}

PALABRAS CLAVE: educación municipal; enseñanza primaria; arquitectura escolar; construcciones escolares; escuela graduada.

ABSTRACT: The attempt to create a modern, universal system of primary education in Spain undertaken by the national government at the beginning of the twentieth century required the construction of thousands of new school buildings. Until 1920, responsibility for building schools lay with the authorities, although the generalised shortage of resources in most councils meant little was achieved. During the twenties and thirties, the State took the construction of new schools into its own hands, although it still required the initiative and cooperation of the municipal authorities. This article analyses the collaboration between local government and the Spanish State to achieve the largest increase in the number of school buildings in the country's history.

KEYWORDS: municipal education; primary education; school architecture; school buildings; graded education. 


\section{Notas sobre la situación de la enseñanza primaria pública en España a comienzos del siglo XX. El camino hacia la forja de una escuela nacional}

En la génesis del sistema educativo español, el nivel de la enseñanza elemental fue el que menos atención gozó por parte del Estado. Hasta comienzos del siglo XX la escuela primaria estuvo en manos de los municipios, limitándose los sucesivos gobiernos centrales a dictar la normativa que debía articular su funcionamiento, pero sin implicarse en su avance, y sin librar los fondos necesarios para auxiliar a las entidades locales en los deberes y cometidos que el Estado le asignaba por medio de la ley. Los consistorios municipales eran responsables del pago de salarios a los maestros, de proporcionarles casa habitación 0 pagar sus alquileres, del mantenimiento de los locales-escuela, de costear sus alquileres, así como el importe de las obras de mejora o construcción de los edificios escolares. Con la creación en 1900 del Ministerio de Instrucción Pública y Bellas Artes y con la asunción por parte del Estado del pago de los salarios de los docentes, el panorama comenzó a cambiar tímidamente, aunque sin el coraje necesario para alcanzar el status del que la enseñanza elemental debería gozar en un sistema educativo moderno.

Como consecuencia de esta despreocupación estatal por la escuela primaria las aulas se encontraban en pésimas condiciones de habitabilidad, ayunas de las exigencias pedagógicas imprescindibles para que en ellas se desarrollase una enseñanza y aprendizaje con un mínimo grado de aprovechamiento. Dentro del paisaje urbano, en el que fácilmente podían distinguirse inmuebles como la iglesia o el ayuntamiento, el edificio-escuela no era identificable a primera vista. ${ }^{1}$ No se reconocía porque no existía, ya que las clases se hallaban disgregadas por habitáculos variopintos, a cual más penoso: la planta baja de los organismos municipales o casas viejas alquiladas. El criterio empleado para seleccionar estos locales solía ser el económico, es decir, que la cuantía precisa para habilitarlos como aula o el alquiler del inmueble resultaran lo menos gravosos posible. ${ }^{2}$ Contadas poblaciones

\footnotetext{
1 "No hay que esforzarse mucho en buscar argumentos que justifiquen la necesidad de una reforma escolar en Barcelona. [....] Las Escuelas públicas municipales están instaladas en locales cuyas deficiencias saltan a la vista. Ni uno solo ha sido construido adecuadamente para el fin al que hoy se le destina. Los más están instalados en pisos de casas particulares cuyas condiciones higiénicas y pedagógicas son a veces vergonzosas. A veces menos intolerables, nunca del todo buenas. Los extranjeros que nos visitan suelen preguntar dónde están nuestras Escuelas públicas, extrañados de no haber visto ninguna construcción escolar como las que hay por todo el mundo, en una capital, por otra parte, en plena fiebre arquitectónica. [...] en una misma clase, en la única clase de la inmensa mayoría de nuestras Escuelas públicas, se reúnen niños de muy variadas edades y muy distinto desarrollo intelectual. Al lado de los pequeñitos que empiezan a deletrear hay adolescentes casi a punto de entrar en la vida social [...] La clase así formada es una masa heterogénea a la que la mejor voluntad del maestro, aun recurriendo al concurso de auxiliares, sólo puede dar un rudimento insuficiente de organización. Cada grupo va por su lado". Ajuntament de Barcelona, Les construccions escolars de Barcelona (Barcelona: Henrich, 1921), obra citada por Cèlia Cañellas, y Rosa Toran, Política escolar de l'Ajuntament de Barcelona, 1916-1936 (Barcelona: Barcanova, 1982), 41-42

2 "La realidad resulta dolorosamente pobre y amenazadora para los niños, tanto, que para que sean instaladas las 758 escuelas o grados que faltan en la provincia como están la mayoría de los actuales, bien puede anhelarse que no se cree ninguna y, todavía más, que sean clausuradas muchas que sólo deben servir de cuadras, gallineros o cabrerizas, si están en bajo, o de graneros o cámaras de trastos si están en alto, porque carecen de volumen, iluminación, aireación, ambiente, horizonte y comodidades necesarias a tiernas criaturas que tienen más derechos que los animales a gozar de tales bienes y a quienes padres inconscientes del peligro, ciegos por
} 
disponían de una escuela pública alzada de nueva planta. Sólo la enseñanza privada, algunas fundaciones particulares auspiciadas por la Iglesia y filántropos de todo tipo habían dispuesto de fondos para levantar un edificio escolar. Esta precariedad generalizada en las infraestructuras escolares públicas impedía no sólo que la enseñanza elemental gozara de una salud aceptable, sino que, además, imposibilitaba el que muchos niños acudiesen a la escuela al no haber plazas suficientes. ${ }^{3}$ Según los datos aportados por C. E Núñez, desde comienzos del siglo XIX en España la demanda de instrucción primaria crecía más rápidamente que la oferta de puestos escolares, al tiempo que desde el último tercio del XIX aumentaba el peso relativo de la escuela privada dentro del nivel elemental, aunque su presencia sería minoritaria y no llegaría a producirse una verdadera competencia entre un sistema y otro, sino más bien una cierta complementariedad. ${ }^{4}$

Mientras que en los núcleos rurales sólo funcionaban escuelas públicas nacionales, en las ciudades éstas coexistían junto con las municipales, que gozaban de autonomía plena, de manera que la solución al problema de falta de plazas escolares y mejores infraestructuras se agravaba por la pervivencia de este modelo municipal/ estatal. Así se describía la situación en un artículo de la revista La Escuela Moderna en 1912:

Lo actual, la impura e ilógica mezcla de Municipio y Estado, conduce a la pintoresca situación que describe el refrán vulgar «el uno por el otro, la casa sin barrer». El uno dice:Yo mando, tú pagas. El otro exclama: Quien paga, manda... Claro es que la municipalización absoluta de la enseñanza primaria tiene en su contra el bochornoso recuerdo de antaño. Siguen adeudando millones por instrucción pública

un afán de cultura a toda costa y faltos de voluntad y ciudadanía para luchar contra tanta injuria para la salud de sus hijos, llevan a semejantes sitios, sin discernir que el mal que acarrean no puede ser aliviado por el bien que pretenden. [...] Un $72 \%$ de locales en que los niños se rebullen penosamente por resbalamiento contra otros compañeros, porque no disponen de la extensión necesaria, viviendo en contacto contaminador de enfermedades para sus cuerpos. Un $88 \%$ de escuelas sin patio, parterre, ni jardín, en que, solazar, sino solazar, por lo menos dar ocasión y ocio para que las clases se ventilen, un $76 \%$ sin retrete con agua [...] No sirve de paliativo a las miserias expuestas que, el $32 \%$ de estos locales tienen superficie y volumen suficientes; que el $37 \%$ de estos locales gozan de luz y ventilación bastante, ya que ni unos ni otros poseen aquellos detalles de construcción, ni aquellos elementos de comodidad que el maestro necesita para una disciplina y orden saludables y para una organización modelo. [...] A pesar de la predicación constante de la Inspección de Primera Enseñanza, a pesar del cálido llamamiento de la Presidencia, los Ayuntamientos de la provincia no se deciden al sacrificio de ofrecer en dinero o en materiales y mano de obra ese mínimo del $25 \%$ con que se contenta el Estado para crear no sólo centros de cultura moderna, cómodos e higiénicos que hagan amable la labor del Maestro y agradable la estancia del niño, sino algo muy positivo para la Administración Municipal, como es la riqueza que representa la renta capitalizada siquiera al $6 \%$ de los alquileres que hoy se pagan". Memoria Plan de Ordenación Escolar de Málaga, 1925. Archivo General de la Administración, Ministerio de Educación, C. 31/ C.6237.

${ }^{3}$ En 1935, en el expediente de solicitud de subvención para la construcción de un nuevo grupo escolar en Santander, la Inspectora de Educación apuntaba: "Según la última estadística resulta que hay más de 16.000 niños que no pueden recibir instrucción por falta de escuelas (20-IX-35)". Archivo General de la Administración, Ministerio de Educación, C. 31/ C.6258

4 "Así, en 1925 el número de alumnos matriculados en las escuelas privadas se había multiplicado por 4 desde 1860, mientras que el de aquellos que asistían a la escuela pública tan sólo había aumentado en un 60 por 100. La escuela privada pasó de ser algo más del 10 por 100 en 1860 a ser aproximadamente el 30 por 100 a mediados de la década de 1920". Clara Eugenia Núñez, La fuente de la riqueza. Educación y desarrollo económico en la España contemporánea (Madrid: Alianza Universidad, 1992), 228 - 259. 
muchos Ayuntamientos, y siguen siendo una vergüenza los locales de escuela que la ley confía a los cuidados de las Cajas municipales. ${ }^{5}$

Las tres primeras décadas del siglo XX se caracterizaron en España por la búsqueda de una fórmula que resolviera y aclarara definitivamente esta dualidad en la asunción de responsabilidades referidas a la instrucción elemental entre el Estado y los municipios. Mientras en las poblaciones pequeñas la situación no admitía alternativas, y se aceptaba como imprescindible la intervención del Estado en la gestión de la enseñanza primaria, en las ciudades los ayuntamientos cederán paulatinamente parte de sus competencias al Estado, en algunos casos con ciertas reticencias, ya que estas enajenaciones suponían una pérdida de autonomía en la dirección de la enseñanza elemental en su término municipal. Sin embargo, las circunstancias y cambios sociales, así como las habituales y generalizadas penurias económicas de las arcas municipales aconsejaban y propiciaban un cambio de rumbo, especialmente en las grandes ciudades, a las que se trasladaban las masas de población rural en busca de trabajo y en las que los ayuntamientos se veían incapaces de abrir escuelas para la numerosa población infantil desescolarizada, que se incrementaba sin cesar. Por ello, durante estos años se produjo un trasvase de competencias referidas a la enseñanza primaria desde los municipios al Estado, aunque éste no llegara a asumir plenamente la responsabilidad de este nivel educativo y subordinara sus ayudas a la iniciativa y gestiones previas de los municipios.

En las líneas siguientes se tratará de exponer cómo en este camino hacia la forja de una escuela nacional gestionada por el Estado el asunto de las construcciones escolares resultaría de capital importancia, sobre todo si se admite la prioridad y necesidad de la universalización de la enseñanza elemental como base de un sistema educativo moderno. Simultáneamente, se intentará poner de relieve la contribución de los municipios a la expansión de la red escolar, que, si bien fue promovida por la administración central, exigió el concurso y colaboración de estas entidades locales.

\section{Las construcciones escolares subvencionadas por el estado, un paso decisivo en la forja de la escuela nacional. El papel de los municipios}

Resulta fácil aceptar que la mejora de la calidad de la enseñanza elemental, así como su universalización constituían cuestiones básicas y urgentes, que no podrían resolverse sin la construcción de miles de escuelas. Sin embargo, en general, los ediles municipales no estaban dispuestos a destinar más fondos a alquilar nuevos locales y, mucho menos, a sufragar la construcción de edificios escolares, ya que las haciendas locales carecían de recursos suficientes y a duras penas podían afrontar los gastos generados por las aulas en funcionamiento. Con este panorama extendido por todo el territorio nacional, la universalización de la enseñanza elemental se tornaba en un objetivo inalcanzable.

\footnotetext{
5 J. Llarena, «Boceto de información mundial pedagógica», La Escuela Moderna, no 246 (1912), 148 y 149, citado por Mํㅡㄹ del Mar del Pozo Andrés, Urbanismo y educación. Política educativa y expansión escolar en Madrid (19001931) (Alcalá de Henares: Universidad de Alcalá, 1999), 178.
} 
Por otro lado, la ciudadanía exigía más y mejores aulas, conocedora de que la enseñanza pública constituía la única tabla de progreso y ascenso social a la que sus hijos podrían asirse, demandando un cambio de escenario para la instrucción elemental como primer paso para conseguir una escuela pública de calidad.

Desde la pérdida de las últimas colonias en 1898, gran parte de los intelectuales españoles del momento coincidieron en señalar que una de las posibles causas de la decadencia nacional provenía de la mala calidad de la enseñanza, por lo que proponían como indispensable y urgente la regeneración pedagógica. Esta propuesta se concretaría en la intención de extender y generalizar la implantación de la escuela graduada dentro del sistema educativo. Dicho y hecho. El primer gobierno conservador constituido tras el desastre de 1898 dispuso la conversión en escuelas graduadas de los centros primarios anejos a las Escuelas Normales, fijándose en tres secciones los niveles en los que se distribuirían los niños, según su edad y cultura, introduciendo, además, nuevos contenidos curriculares, así como la figura del Director como máximo responsable de los nuevos centros. Aunque fueron muchos los que opinaban que el nuevo modelo organizativo no exigiría mejorar ni incrementar las infraestructuras disponibles, sino solamente captar su espíritu y ponerlo en práctica en las aulas existentes, otros grupos de profesionales e intelectuales defendieron la necesidad y conveniencia de levantar edificios acordes con la escuela graduada, como requisito ineludible para que se produjera la tan deseada mejora en la calidad de la enseñanza.

Tanto las propuestas de los intelectuales regeneracionistas como las reivindicaciones ciudadanas, aderezadas por el propósito del Estado de introducir y generalizar la escuela graduada en España, constituirían el caldo de cultivo que empujaría a la administración central a modificar sustancialmente su postura respecto a su implicación en la financiación de las infraestructuras escolares, a romper la secular desidia del Estado español en este asunto. Es necesario matizar, sin embargo, que su objetivo se supeditó a la acción de los municipios, ya que, como se verá más adelante, sin el impulso y cooperación de las entidades locales no se podrían iniciar ni adelantar los trámites relativos a la construcción de un nuevo edificio escolar.

Se percibía como un sentir generalizado que sin una enseñanza elemental universal y de calidad España no podría escapar del atraso económico en el que se hallaba sumida en los primeros años del siglo XX. Mejorar e incrementar las infraestructuras escolares públicas sería una empresa a la que se entregarían, con más o menos pasión y acierto, municipios, Diputaciones provinciales, Estado y sociedad, además de otras instituciones como el Instituto Nacional de Previsión y sus Cajas de Ahorro colaboradoras. Este era un asunto decisivo para la consolidación de la idea de escuela nacional ligada al Estado, amparado por dos regímenes tan distintos como la Dictadura de Primo de Rivera y la II República, que modificaría la valoración de la enseñanza primaria dentro del sistema educativo español.

Las graves deficiencias que aquejaban y lastraban el desarrollo del nivel elemental de enseñanza en España exigían una intervención directa y resuelta del Estado, asumiendo 
gran parte de las tareas que hasta entonces había encomendado a los municipios. Durante las tres primeras décadas del siglo XX la administración central desvelará su protocolo de actuación y paulatinamente lo irá llevando a la práctica. Su intención de involucrarse cada vez más en el control, dignificación y crecimiento de la enseñanza primaria será el hilo conductor de sus actuaciones, relegando a los municipios al papel de coprotagonistas forzosos del cambio. Para conseguir su propósito promovería cambios legislativos y económicos encaminados a animar, a exhortar, casi a conminar a las corporaciones municipales a participar en esta empresa.

Como requisito previo para lograr la dignificación y universalización de la enseñanza primaria pública resultaba imprescindible conseguir la mejora y expansión de las infraestructuras escolares: sin más y mejores aulas, la enseñanza elemental continuaría en su secular estado de postración. Por ello, en el terreno económico, el Estado reservará en sus presupuestos cada vez más fondos para el alzado de nuevas escuelas, incluso concertará créditos extraordinarios a tal fin, aunque sin prescindir de la aportación económica municipal. Aun así, durante estos años se produjo un gran salto cuantitativo: si hasta entonces los ayuntamientos debían costear la totalidad del importe de las obras del nuevo edificio escolar, en los años veinte se pasó a tener que hacer frente únicamente a la cuarta parte del total presupuestado, asumiendo el Estado el resto de la cuantía. De esta forma se destensaba uno de los frenos que hasta entonces había impedido la expansión de la red de edificios escolares, si bien es cierto que no sería hasta 1926 cuando el Estado libraría cantidades significativas.

En el terreno legislativo, tres dimensiones básicas enmarcarían la labor estatal. La primera, referida a la dignificación del espacio escolar, impulsaría a la administración central a dictar una normativa detallada con el objetivo de que la construcción de edificios-escuela se atuviera a una serie de criterios pedagógicos, higiénicos y técnicos, considerados como imprescindibles para garantizar una buena práctica escolar. En 1920 se creó un organismo regulador que velaría y controlaría la calidad e idoneidad de los nuevos edificios. Se trataba de la Oficina Técnica para Construcción de Escuelas. ${ }^{6}$ Sus funciones abarcarían desde la redacción y ejecución de los proyectos de escuelas construidas por el Estado, hasta el examen e informe de cuantos edificios y locales se construyeran y/o destinaran a enseñanza primaria por los ayuntamientos, asegurando que se cumplieran las instrucciones técnico-higiénicas fijadas como indispensables para la praxis escolar. La segunda línea fijaría los trámites administrativos a los que deberían ajustarse los municipios interesados en levantar escuelas, si aspiraban a contar con el auxilio económico a fondo perdido que el Estado les brindaba. ${ }^{7}$ Una tercera dimensión sería la relativa a la financiación de la aportación municipal. A partir de 1924 se abrirían nuevas vías de crédito, singularmente a través del Instituto Nacional de Previsión y sus Cajas de Ahorro colaboradoras, con el propósito de que los consistorios dispusieran de liquidez o financiación para asumir su contribución al presupuesto de las obras de construcción.

\footnotetext{
${ }^{6}$ R.D. de $23 / \mathrm{XI} / 1920$.

${ }^{7}$ Entre ellos destacamos: R. D. de 23/XI/1920; R.O. de 31/V/1921; R.D. de 3/II/1922; R.D. de 17/XII/1922.
} 
El cometido que casi en exclusiva habían jugado hasta entonces las entidades municipales en este asunto se mostraba claramente insuficiente para los retos que la sociedad del nuevo siglo demandaba: o el Estado tomaba las riendas en la extensión de las infraestructuras escolares o el atraso que la nación presentaba en relación con el resto de Europa se iría acrecentando cada vez más. En un primer momento, el Estado se lanzó a la construcción de edificios escolares asumiendo íntegramente los gastos, asignando a los ayuntamientos tareas como la de facilitar el solar en el que se asentaría el nuevo edificio y el campo escolar, la de dotar al edificio del caudal de agua preciso y conducirlo hasta el mismo solar, así como la de facilitar el alcantarillado o en su caso las instalaciones precisas para la eliminación de materias residuales, compra de material y mobiliario, así como otras prescripciones que aseguraran la viabilidad del edificio alzado. ${ }^{8}$ El único inconveniente que presentaba esta línea de actuación provenía de la inexistencia de un presupuesto lo suficientemente elevado como para atender el volumen de necesidades. Faltaban edificios escolares en todas las localidades españolas. Los niños sin escolarizar pululaban por las calles de las ciudades, que incrementaban su población durante estos años, sin ser atendidos por los municipios, desbordados por otras cuestiones como la urbanización de los nuevos asentamientos poblacionales. En la España rural también se precisaban más plazas escolares, aunque quizá aquí la urgencia quedaba cercenada o disimulada por la utilidad de la mano de obra infantil.

A esta primera intervención de la administración central seguiría una postura más realista y pragmática. El Estado continuaría levantando escuelas, pero los municipios debían costear al menos la cuarta parte del presupuesto de ejecución de obras. Solo en casos de suma pobreza o de poblaciones de menos de 500 habitantes el Estado asumiría todos los costes. Además, se comprometía a subvencionar, con un $75 \%$ del total presupuestado y a fondo perdido, las obras que los ayuntamientos emprendiesen por su cuenta, aunque en un primer momento se inclinaría sólo por auxiliar las obras de edificios destinados a escuelas graduadas, otorgándoles una subvención de 10.000 Ptas. por cada sección de graduada edificada.

Aunque estas medidas modificaron significativamente la implicación del Estado en el asunto de las construcciones escolares, la dualidad en el reparto de responsabilidades no se rompió, puesto que la iniciativa de levantar una nueva escuela siempre estuvo en manos municipales. Proporcionar el solar, incoar y tramitar el expediente de construcción de un edificio escolar, así como solicitar el auxilio económico del Estado debía partir siempre del consistorio municipal respectivo. Además, a través de la legislación promulgada la administración central exhortaba a las corporaciones municipales que no contaran con suficientes edificios o con locales-escuela en condiciones aceptables, a construirlos o facilitarlos en el plazo de cinco años, advirtiendo de que en caso de incumplimiento el Estado realizaría las

\footnotetext{
${ }^{8}$ Los ayuntamientos no tendrían que entregar cantidad alguna para la construcción del edificio escolar, que sería propiedad del Estado, pero sí estarían obligados a invertir en material fijo una cantidad que no podría ser inferior al $8 \%$ del coste total del edificio. Otras atenciones serían el mantenimiento de los edificios-escuela, debiendo consignar en el presupuesto municipal una cantidad no inferior al $1 \%$ del coste total del edificio, así como la exigencia de proporcionar casa a los maestros.
} 
obras precisas, y después cargaría su importe al municipio. ${ }^{9}$ Pese al tono conminatorio de esta norma, parece que la amenaza no trascendió, y no se conoce ningún caso en el que se actuara en consecuencia.

Sucesivas disposiciones seguirían perfilando el asunto, detallando los pasos a seguir por los consistorios en el caso de alzar un nuevo edificio en colaboración con el Estado, y dejando bien definidas las dos posibles modalidades de acceso a las ayudas a fondo perdido: o bien el municipio realizaba las obras y reclamaba el auxilio económico del Estado, o bien el ayuntamiento solicitaba la ejecución de obras al Estado, comprometiéndose previamente a colaborar asumiendo un porcentaje de los gastos. ${ }^{10} \mathrm{~A}$ la primera modalidad podría denominársela como 'construcción municipal', y a la segunda, 'construcción directa' o 'tutelada por el Estado', bien entendido que en ambos casos el consistorio era el promotor de la erección del nuevo edificio. En las dos modalidades, el gobierno central, como norma general, aportaría el 75\% del valor de la construcción, y el municipio la cuantía restante, el solar y, además, se responsabilizaría de las obras de alcantarillado y urbanización. A pesar de estos incentivos, hay que precisar que para muchas corporaciones constituía un obstáculo insalvable la aportación del $25 \%$ del presupuesto de ejecución de obras, y que la cuantía destinada en los presupuestos del Ministerio de Instrucción Pública a la empresa se agotaba rápidamente, quedando sin atender y pospuestas para ejercicios ulteriores las demandas de numerosos municipios. Los dos inconvenientes serían subsanados progresivamente.

El cambio político introducido por el comienzo de la Dictadura se dejó notar en muchos campos de la vida española, también en el ámbito escolar. El deseo expresado por las autoridades del momento de favorecer la modernización del país mediante la mejora de las infraestructuras públicas alcanzó también al asunto de la construcción de escuelas y cristalizó en la intensificación y formalización de vías de financiación novedosas a través del Instituto Nacional de Previsión y sus Cajas de Ahorro colaboradoras. Estas formas de financiación facilitaron la construcción de numerosas obras públicas de carácter social, entre ellas centros escolares. En este sentido hay que enmarcar la creación en 1924 de la Junta para el Fomento de Construcción de Escuelas Nacionales, entidad con la que se define y formaliza el papel del Instituto y sus Cajas en el tema, y que agilizaría el ritmo de construcción de nuevas escuelas. Además, a partir de 1926 se elevaría la dotación económica estatal para este asunto mediante el concierto de un crédito de cien millones de pesetas, distribuido en diez ejercicios. Esta inyección de capital se traduciría en un incremento notable de nuevos proyectos. Dos años después, el Estado daría otro paso decisivo al disponer, mediante el R.D de 10/VII/ 1928, que las poblaciones de menos de 10.000 habitantes interesadas en levantar escuelas unitarias por la modalidad de construcción municipal podrían gozar también de una subvención a fondo perdido. ${ }^{11}$ En el desarrollo

\footnotetext{
${ }^{9}$ R.D. de $3 / I I / / 1922$.

${ }^{10}$ R.O. de $26 / / / 1923$.

${ }^{11}$ Recordemos que hasta entonces sólo los edificios que albergasen escuelas graduadas podían optar a una subvención, ya que las escuelas unitarias sólo podrían construirse por el Estado, y si eran levantadas por los ayuntamientos no contaban con ningún auxilio económico estatal. Las notas más sobresalientes de este decreto eran las siguientes: La extensión de las subvenciones a las escuelas unitarias, 9.000 Ptas. por escuela unitaria,
} 
del decreto se apuntaba la creación de una Comisión de Construcciones Escolares en cada provincia, presidida por el Gobernador Civil e integrada por cuatro vocales natos, el Presidente de la Diputación, el Arquitecto Escolar Provincial, el Inspector Jefe Provincial, y el Jefe de la Sección Administrativa, así como otros cuatro vocales, dos de ellos femeninos, nombrados por el Ministerio de Instrucción Pública a propuesta de los vocales natos, elegidos entre aquellas personas que se hubieran distinguido por su cariño a la niñez y a la educación. Tendrían como misión recabar las informaciones y datos necesarios para configurar la ordenación escolar de cada provincia, valorando el número, tipología y estado de los edificios-escuela existentes, así como las necesidades de arreglos, adaptaciones o de nuevas construcciones escolares indispensables para garantizar tanto la plena escolarización como una mínima calidad de enseñanza en los locales escuela que estaban ya en funcionamiento. Sus conclusiones se resumirían en unos informes enviados a la Dirección General de Primera Enseñanza. Aunque a primera vista la implantación de estas Comisiones pudiera responder a la intención de planificar a nivel provincial la expansión de la red escolar, parece que se limitaron a enviar a la Dirección General de Primera Enseñanza las solicitudes debidamente cumplimentadas que llegaron a sus manos, porque lo cierto era que todas las localidades necesitaban nuevas escuelas.

La primera disposición relativa a las construcciones escolares de la etapa republicana llegó a los pocos meses del advenimiento del nuevo régimen, mediante el Decreto de 7 / VIII/1931. Con esta norma se buscó atender las peticiones de aquellos municipios con menos recursos económicos, así como sistematizar la concesión de ayudas y subvenciones atendiendo a la capacidad económica del municipio, establecida ésta en forma de módulos fijados aritméticamente en los que se evaluaban los factores siguientes: la riqueza relativa del municipio, el esfuerzo realizado para contribuir por encima del coeficiente que por razón de su riqueza le correspondía abonar y, finalmente, la necesidad de escuelas que hubiera en la localidad en relación directa con el número de analfabetos. ${ }^{12}$ También se

10.000 Ptas. si disponía de casa-habitación para el maestro, y 10.000 Ptas. por cada sección de escuela graduada, no siendo nunca la aportación del Estado superior al 75\% del total del coste de las obras, salvo en caso extremo. En estos casos el titular sería el municipio. La posibilidad de que la vivienda de los maestros se construyera en el mismo edificio de la escuela, pero sin comunicación con ella. La inspección de las construcciones se realizaría en dos momentos: antes de que el edificio estuviera enfoscado para comprobar los materiales y condiciones de seguridad, y cuando las obras ya estuvieran terminadas. Para las construcciones que hubiera de realizar el Estado serían preferidas las solicitudes que ofrecieran mayores aportaciones en proporción al coste de las obras. Para las construcciones que realizaran los ayuntamientos la preferencia se determinaría a favor de los que demandaran menor subvención. El Estado podría conceder subvenciones mayores de las fijadas o realizar construcciones con menor aportación del municipio o sin ninguna, en casos de pobreza o hechos memorables de su historia. Para aquellas Comisiones Provinciales de Construcciones Escolares que solicitaran un plan conjunto se distribuiría la suma global de la subvención en dos o más anualidades. El texto del decreto recogía, además, la posibilidad de que los ayuntamientos con edificios escolares finalizados con anterioridad a la promulgación de esta norma pudieran acogerse a las nuevas subvenciones, incluidos los que hubieran levantado escuelas unitarias. Por ello, fueron muchos los pequeños municipios que habiendo costeado íntegramente las obras de su nueva escuela solicitaron la subvención estatal, tras la entrada en vigor de esta disposición.

${ }^{12}$ La capacidad económica se determinaba con arreglo a los siguientes parámetros: a) Se deduciría de la suma de ingresos del presupuesto ordinario del municipio: 1) La suma de partidas de orden, 2) Los recursos procedentes de operaciones de crédito y 3) Los ingresos debidos a enajenación de bienes, a menos que fueran 
contemplaba la posibilidad de que el ayuntamiento contribuyera con menos del $25 \%$ del coste total de las obras, mínimo exigido hasta entonces. El complemento económico para la materialización de esta normativa llegó mediante la Ley de 16 de septiembre de 1932, que disponía la emisión de 400 millones de Deuda Pública con el propósito de emplearlos en construcciones escolares, el 10\% para edificios no destinados a la primera enseñanza, y el $90 \%$ restante para escuelas de nueva planta, subvenciones a los ayuntamientos, reparación, conservación y adaptación de edificios como escuelas. Con fecha 1 de diciembre de 1932 se emitieron las primeras obligaciones del llamado Plan Nacional de Cultura.

El destino de este efectivo quedaría fijado en el Plan de Construcciones, en el Decreto de 5 de enero de 1933. A partir de su entrada en vigor en las construcciones ejecutadas por el Estado se tendría en cuenta la capacidad contributiva del municipio, mediante la creación de una escala de situaciones en la que se contemplaba una variación de 0 a 50, fijándose el mínimo de aportación municipal obligatoria en el $5 \%$ y el máximo en el $50 \%$. Hay que tener en cuenta, además, que la aportación estatal no podía exceder las 20.000 Ptas. por grado, por ser ésta la cifra que sirvió de cálculo para fijar en 400 millones las 20.000 escuelas, es decir aulas, que el Plan se proponía edificar en cinco años. Este número de aulas se había fijado como el mínimo necesario para cubrir las necesidades de escolarización universal. Otra de las novedades del Plan la constituía la posibilidad de que en los grupos escolares graduados se subvencionasen las dependencias anejas, comedor, bibliotecas, museos, dispensarios médicos, etc. En el Plan se mantuvieron las dos modalidades de ejecución: la edificación directa por el Estado, así como la ejecución de obras por parte de los ayuntamientos, que después percibirían la subvención estatal. Se mejoró esta modalidad elevando la cuantía del auxilio económico de 9.000 a 10.000 Ptas. para las unitarias, de 10.000 a 12.000 Ptas. para las unitarias con vivienda de maestro, y de 10.000 a 12.000 Ptas. para las aulas o dependencias anejas, cantinas, museos, bibliotecas, etc. en los centros escolares graduados.

Con el cambio de gobierno producido en el segundo bienio no decreció el interés por la cuestión, aunque se modificaron algunos aspectos relativos a las contribuciones municipales, a las subastas de obras, así como a las condiciones técnico-higiénicas. El Decreto de 15 de junio de 1934 exhortaba, incluso conminaba, a los ayuntamientos con localesescuela inadecuados a que se embarcasen en la empresa de construcción de nuevas escuelas. Para ello se ofrecía la posibilidad de proyectar edificios más sencillos, y por tanto más baratos, simplificando los requisitos técnicos a los que debían ajustarse los proyectos. ${ }^{13}$ Con la entrada en vigor de este decreto se eliminaba la escala anterior, y se adoptaba una nueva en función del número de habitantes, de tal manera que los ayuntamientos que no excedieran de los 500 habitantes aportarían sólo el 10\% de las obras; el 15\% cuando sobrepasaran los 500 y no llegasen a los 2.000 ; el 20\% si excedían los 2.000 y no rebasa-

sobrantes de la vía pública. b) Lo que restara del presupuesto ordinario de ingresos serviría para precisar la cuota con que cada habitante de hecho contribuía a la formación de dicho presupuesto, y reflejaba, por tanto, su capacidad económica.

${ }^{13}$ En la O.M. de 28/VII/34 se exponían dos tipos de condiciones técnico-higiénicas, unas referidas a las condiciones ideales a las que debía tender toda construcción escolar, y otras señalando los requisitos mínimos que toda construcción debía reunir. 
ban los 10.000 habitantes. Se había optado, pues, por obviar la situación económica del municipio y basarse en criterios demográficos a la hora de otorgar los auxilios económicos. De la regla anterior se exceptuaba a los municipios de extrema pobreza.

Tras las elecciones de febrero de 1936, con Marcelino Domingo al frente del Ministerio de Instrucción Pública, se promulgaron nuevas normas: el D. /7/II/36, que exigía añadir al expediente de construcción una certificación del acuerdo municipal en el que se designara al arquitecto-director, así como la OM./18/II/36, que regulaba nuevamente la tramitación de los expedientes de construcción. A partir de esta fecha se concederían 5.000 Ptas. de subvención para viviendas de maestros a los municipios de menos de 6.000 habitantes.

\section{Coordenadas espacio-temporales en la expansión de la red escolar pública, 1920-1937}

¿Cómo cristalizaron las medidas anteriores? ¿Fueron efectivas? ¿Cuánto y cómo influyeron las instituciones municipales en la expansión de la red escolar? ¿Cuántas escuelas se alzaron durante estos años?

Para responder a estas preguntas he de referirme a una exhaustiva investigación que he realizado, en la que se documenta y estudia la expansión del parque español de edificios escolares públicos durante el intervalo temporal comprendido entre 1922 y $1937 .{ }^{14}$ Aceptar la veracidad y fiabilidad de los datos que se expondrán a continuación exigen del lector la confianza en la autora, que dada la limitación de espacio no puede incluir el aparato crítico que avala las cifras y conclusiones expuestas.

Durante la década de los años veinte comienzan a emerger en España una serie de magníficos edificios escolares públicos, con mayor intensidad y a un ritmo más acelerado que en años precedentes. Naturalmente, este cambio no se realizó en un abrir y cerrar de ojos, ni obedeció sólo a la entrada en vigor de dos o tres decretos ministeriales, sino que fue un proceso complejo, favorecido por diversas circunstancias y en el que se implicarían varios agentes, entre los que sobresalen los ligados a la institución municipal.

Si bien durante estos años el Estado se comprometía a donar a fondo perdido cantidades que rondaban el $75 \%$ del coste presupuestado del nuevo edificio escolar, se dejaba en manos de los ediles municipales la potestad de pulsar el botón de inicio, tanto de la tramitación del expediente de construcción, que desembocaría en la concesión de auxilios económicos, como del comienzo de las obras. Esta delegación de responsabilidades por parte de la administración central nos inclina a mantener que el desarrollo y ritmo del proceso de mejora e incremento de las infraestructuras escolares obedeció en mayor grado a la gestión municipal que a la del propio Estado. Aunque son muchos los que se empeñan en afirmar que corrientes políticas determinadas, singularmente las ligadas a los ideales republicanos, impulsaron más decididamente que otras ideologías o regímenes las construcciones escolares, lo cierto fue que durante esta etapa tanto los gobiernos conformados durante la Dictadura de Primo de Rivera como los constituidos durante la II República promovieron el alzado de nuevas es-

\footnotetext{
${ }^{14} \mathrm{M}^{a}$ del Pilar García Salmerón, Radiografía de las construcciones escolares públicas en España, 1922-1937 (Madrid: Ministerio de Educación y Formación Profesional, 2018).
} 
cuelas, dispusieron los fondos para ello y asumieron la empresa como un asunto de Estado, aunque siempre subordinado a la iniciativa y gestión municipal. El impulso de la administración central al asunto habría resultado estéril sin el apoyo y cooperación de los ayuntamientos, conformados por ediles de todas las tendencias políticas. Considerando, además, que las ideologías parecen estar menos arraigadas dentro de las corporaciones locales que en los gobiernos nacionales, y que en los consistorios municipales los intereses y anhelos ciudadanos encuentran un eco más cercano y directo, no resulta muy descabellado afirmar que fue un aliento social, canalizado a través de los municipios, el factor más decisivo en el crecimiento del parque público de edificios escolares. Realmente los gobiernos centrales y las ideologías que los animaban tuvieron menos importancia de la que se les suele atribuir en gran parte de la bibliografía sobre el tema.

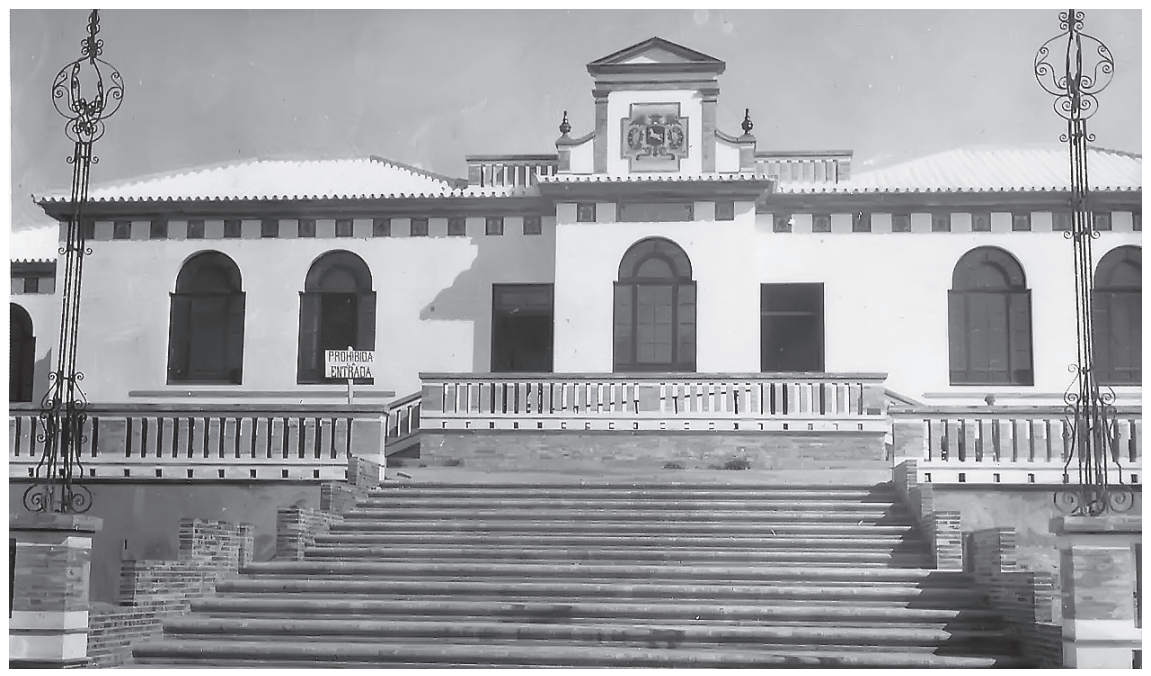

Fotografía 1: Escuela de Morón de la Frontera (Sevilla), 1930. Fuente: Ministerio de Cultura y Deportes. Archivo General de la Administración. Fondo de Educación. 31/ C. 6367.

Durante esta etapa la proporción de edificios costeados íntegramente por el Estado fue muy pequeña. Como ya se ha comentado, durante algunos años el Estado asumió el coste íntegro de las escuelas levantadas en poblaciones de menos de quinientos habitantes, las de algunos municipios de extrema pobreza, así como, especialmente durante la II República, las de una decena de grupos escolares ubicados en poblaciones singulares, cuna de hombres ilustres o sede de hechos históricos considerados como relevantes por el régimen. El resto de escuelas exigió la iniciativa, impulso y colaboración de las entidades municipales, de tal manera que tanto el ritmo como la forma de la nueva red escolar serían dictados por los municipios, mucho más que por los sucesivos gobiernos centrales.

También es preciso apuntar que durante la década de los años veinte más de un centenar de municipios, amparados por el Instituto Nacional de Previsión y sus Cajas de Ahorro, consi- 
guieron alzar, sin ningún auxilio económico del Estado, más de doscientos edificios escolares, por lo que no nos parece desacertado afirmar que las entidades municipales fueron las instituciones pioneras en la tarea de dignificación y extensión de la red escolar pública. Tampoco resulta muy aventurado aceptar como sentir generalizado el deseo de los pueblos y ciudades de España por optimizar su microsistema-educativo. A medida que se alzaban las nuevas escuelas, una especie de fiebre contagiosa se propagó por muchas plazas españolas. Nadie quería ser menos que nadie. Contar con un buen inmueble escolar parece que se convirtió tanto en garantía de un futuro mejor para los ciudadanos más menudos como en señal inequívoca de los desvelos de los concejales por sus convecinos. La nueva escuela representaría dentro del patrimonio local una pieza emblemática, quizá la más moderna y práctica, dentro de las que originaban y resaltaban el indiscutible orgullo local. Así se exponía en la temática y argumentación de los discursos de las autoridades locales que adornaban las inauguraciones de los nuevos edificios. Frecuentemente, en esos textos se insistía sobre la trascendencia de la nueva escuela, punto de inflexión que señalaría el comienzo de una nueva era, el signo más evidente y palpable de que la modernidad había llegado a la localidad. Ciertamente los ideales y propuestas regeneracionistas habían calado en gran parte de la sociedad española y los ediles buscaron materializarlos en su término municipal, logrando el mayor incremento del número de aulas de nueva planta en la historia del sistema educativo español.

\begin{tabular}{|c|c|c|c|c|}
\hline & $\begin{array}{c}\text { Edificios } \\
\text { proyectados }\end{array}$ & $\begin{array}{c}\text { Aulas } \\
\text { Proyectadas }\end{array}$ & $\begin{array}{c}\text { Edificios } \\
\text { Terminados }\end{array}$ & Aulas terminadas \\
\hline $\begin{array}{c}\text { A } \\
1920 / 1931\end{array}$ & 200 & 500 & 200 & 500 \\
\hline $\begin{array}{c}\text { B } \\
1922 / 1931\end{array}$ & 1.035 & 3.986 & 991 & 3.709 \\
\hline $1922 / 1931$ & 1.235 & 4.486 & 1.191 & 4.209 \\
\hline $\begin{array}{c}\text { A } \\
1931 / 1937\end{array}$ & 1 & 24 & 1 & 24 \\
\hline $\begin{array}{c}\text { B } \\
1931 / 1937\end{array}$ & 2.322 & 9.708 & 713 & 2.929 \\
\hline $1931-37$ & 2.323 & 9.732 & 714 & 2.953 \\
\hline
\end{tabular}

Tabla 1. Edificios y aulas públicas proyectadas y/o terminadas en España, 1920-1937. A) Edificios sufragados en exclusiva por los ayuntamientos. B) Edificios que contaron con auxilio económico estatal. Fuente: Elaboración propia.

A modo de resumen, conviene dejar claro que corporaciones locales de todas las tendencias políticas, desde principios de los años veinte, tanto durante la Dictadura como en la etapa republicana, sin solución de continuidad, trabajaron por mejorar e incrementar el conjunto de edificios escolares públicos. Según los datos manejados en la investigación aludida, el resultado final de este empeño común puede resumirse en las cifras siguientes: 
En los años veinte se alzaron en España en torno a mil doscientos edificios escolares, en los que tendrían cabida más de cuatro mil aulas. Durante la II República se concluyeron las obras de unos setecientos edificios escolares, en los que se instalarían unas tres mil aulas.

En cuanto a la distribución de las nuevas escuelas por el territorio nacional es preciso señalar que fue muy irregular. La variedad abarcaba desde municipios que incrementaron notablemente el número de aulas, hasta otros en los que no se construyó ni una sola clase; desde provincias con un incremento significativo en el número de nuevas escuelas, a otras que levantaron un número muy reducido. En segundo lugar, es preciso destacar las diferencias en el trato o consideración otorgado por el Estado a los municipios según su número de habitantes o capacidad económica. En general, las ayudas favorecieron a los grandes núcleos de población, singularmente a Madrid, que si bien veían incrementarse su población escolar durante estos años, y por tanto precisaban más aulas, también es cierto que en general disponían de más recursos. Los municipios de mayor riqueza gozaron de un trato de favor, ya que el Ministerio de Instrucción Pública dio prioridad a las peticiones de aquellos consistorios que se ofrecían a colaborar con una cuota mayor al total del presupuesto. También los pueblos de menos de 500 habitantes disfrutaron de una atención especial por parte del Estado, al estar exentos de contribuir con cantidad alguna, durante algunos años, o exigiéndoles aportaciones de menor cuantía. Lo cierto fue que el presupuesto destinado por el Estado para estas pequeñas localidades se agotaba rápidamente, y muchas poblaciones quedaban relegadas para ejercicios posteriores.

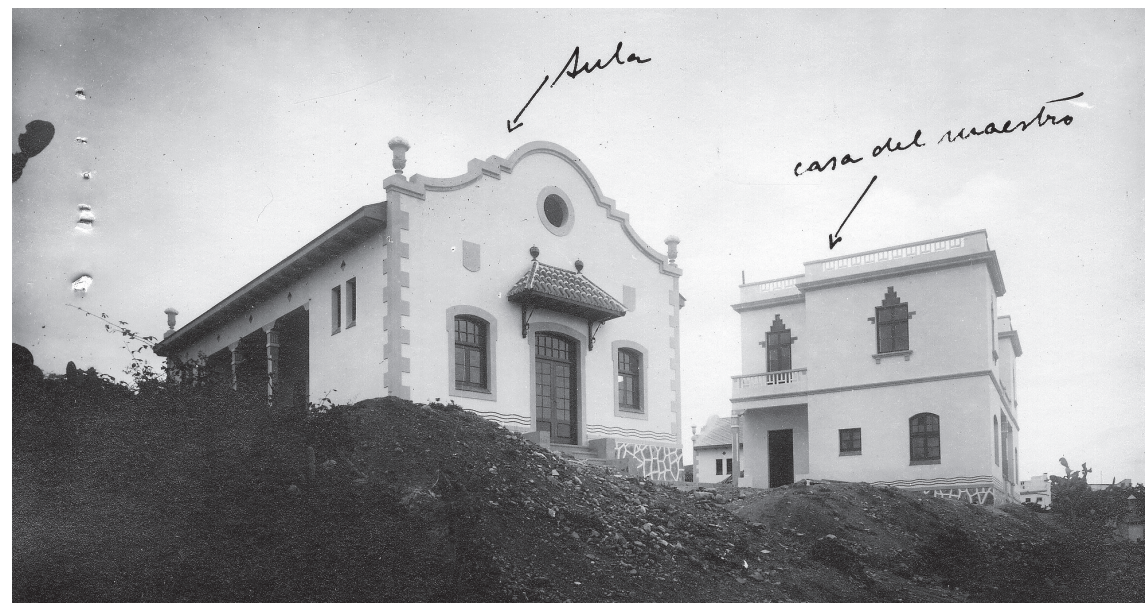

Fotografía 3. Escuela y casa de maestro de Tafira (Las Palmas), 1930. Fuente: Ministerio de Cultura y Deportes. Archivo General de la Administración. Fondo de Educación. 31/ C. 6359.

El Estado dispuso para las ciudades una modalidad singular de subvención, los denominados planes-locales. Desde 1920 se autorizaba a los municipios de más de 50.000 habitantes a redactar planes locales, en los que se contemplaran todas las necesidades de 
infraestructuras escolares de la población. ${ }^{15}$ Dos años después se redujo el censo mínimo para poder confeccionar estos planes, incluyendo a los municipios con más de veinte mil habitantes, de tal suerte que, si resultaba aprobado el plan, el ayuntamiento contaría con una subvención del $50 \%$ del importe de las obras proyectadas. ${ }^{16}$ Los consistorios que optaran por esta vía debían elaborar un proyecto global, en el que quedara justificada la necesidad de nuevos edificios escolares en su localidad. En él se detallaría el número y ubicación de los edificios-escuela que sería preciso construir para atender a la población infantil no escolarizada, se adjuntarían los proyectos arquitectónicos, así como el presupuesto del total de las obras. Si el Estado daba curso al expediente se concedería la ayuda económica a fondo perdido, que se percibiría en varios ejercicios a medida que se justificase la ejecución de obras.

Ubicados entre las ciudades que podían elaborar un plan local de construcciones y los pequeños núcleos de población, se encontraban miles de municipios de tamaño medio, con infraestructuras escolares penosas, que debían ajustarse a la normativa general y sufragar la cuarta parte del presupuesto de ejecución de su nueva escuela. En estos casos resultó trascendental la orientación y respaldo que los ediles municipales recibieron de la Inspección Educativa, de las Juntas Provinciales de Construcciones Escolares, de los consejeros de las Cajas de Ahorro, así como de las Diputaciones respectivas, que asesoraron y alentaron a los concejales en la tramitación del proyecto de construcción. Las grandes disparidades provinciales que se observan en cuanto al número de escuelas quizá pudieran obedecer a la mejor o peor gestión de estos agentes intermedios entre el Estado y los consistorios.

Para valorar esta cuestión se ha recurrido a los datos obtenidos a partir de la suma de edificios y aulas realizados por los municipios de cada circunscripción provincial, entresacados de la investigación que hemos realizado, citada anteriormente. ${ }^{17}$ En este trabajo se detecta que las provincias que más aulas alzaron durante los años veinte son también las que más aulas levantaron durante la II República, lo que parece desligar el asunto de la expansión de la red escolar de connotaciones ideológicas, derivadas del signo político del gobierno central. Más bien se tiene la impresión de que la actuación de una serie de agentes intermedios, desde los Inspectores de Primera Enseñanza a los consejeros de las Cajas de Ahorro, así como algunas instituciones provinciales, las Diputaciones y las Juntas Provinciales para el Fomento de Escuelas, incluso ciertas asociaciones de padres, actuaron a modo de catalizadores del proceso, y sus intervenciones resultaron decisivas a la hora de conseguir que los ayuntamientos se decidieran a emprender la construcción de escuelas. No se explican de otra manera ni las disparidades observadas en este asunto entre municipios semejantes en cuanto a riqueza y población, ni entre provincias con características socio-económicas muy parecidas. Así, dentro del panorama nacional destacan por el número de escuelas alzadas las poblaciones de las provincias enmarcadas en las regiones extremeña, aragonesa, valenciana y catalana, así como las localidades de las provincias balear, salmantina, toledana,

\footnotetext{
${ }^{15}$ R.D. de 23/XI/1920, Artículo 19.

${ }^{16}$ R.D. de $17 / X I I / 1922$.

${ }^{17}$ Mª del Pilar García Salmerón, Radiografía de las construcciones escolares públicas en España, 1922-1937...
} 
murciana y algunas provincias andaluzas, así como las provincias vizcaína ${ }^{18}$ y guipuzcoana ${ }^{19}$ respaldadas por su Diputación. Frente a ellas destacan otras, como las provincias gallegas, la gaditana o la almeriense, en las que prácticamente no se construyó nada. Todo ello pone de manifiesto las limitaciones o deficiencias de la iniciativa municipal a la hora de enfrentarse a la construcción de escuelas, así como la importancia de estos agentes intermedios, que supieron ofrecer a los ediles el respaldo y asesoramiento precisos para enfrentarse a la empresa de construir un edificio escolar.

Así parece confirmarlo el caso de la provincia de Cáceres, en la que se desarrolló un Plan de ámbito provincial, gestionado entre 1925 y 1929, a instancias de tres instituciones que conjugaron sus desvelos y competencias con el propósito de expandir la red provincial de edificios escolares. Este triunvirato conformado por la Caja de Ahorros Extremeña, la Inspección de Primera Enseñanza y la administración local, representada por la Asamblea de Alcaldes de la provincia, desarrolló una labor extraordinaria y ejemplar. Estas provincias presentaban uno de los porcentajes más bajos de escuelas en relación con el número de habitantes, y uno de los índices de analfabetismo más elevado entre las provincias españolas. Achacar y correlacionar estos datos era tarea sencilla, buscar la solución no resultaba tan fácil. Desde luego, sería imprescindible levantar más edificios escolares, mejorar las condiciones de los ya existentes y aunar voluntades para que este propósito llegara a hacerse realidad. Analizando la legislación vigente, los responsables de la Caja, los alcaldes, así como la Inspección se percataron rápidamente de que el recurso a la construcción tutelada por el Estado resultaba una vía posible, aunque muy lenta, por lo que lo más práctico sería favorecer la construcción por parte de las entidades locales. La escasa liquidez, por no decir suma pobreza, de las arcas municipales de los pueblos extremeños impelía inexorablemente a buscar la financiación en la Caja Extremeña. A poner estas ideas en orden y a clarificar la situación real, tanto la esco-

\footnotetext{
${ }^{18}$ A finales de 1920 la Diputación Vizcaína diseñó un Plan de Construcción de Escuelas con el propósito de hacer presente la escuela pública en los caseríos más retirados de los núcleos de población. Se trataba de levantar pequeñas escuelitas, denominadas escuelas de barriada, ubicadas estratégicamente con la finalidad de evitar largos desplazamientos a los niños de los caseríos. La institución provincial se fijó como meta la construcción de cien edificios escolares de varias tipologías, aunque la mayoría respondería al modelo de escuela mixta, con una sola aula. Para financiar el Plan la Diputación contaría con el auxilio de la Caja de Ahorros Vizcaína, que prestaría los fondos precisos a un interés no superior al 5\%. Hasta 1926 se habían levantado 77 edificios-escuela, se habían construido 114 aulas, a las que asistían más de 4.748 alumnos. En 1926 se alzarían 13 edificios más. En este micro-plan no se recurrió al auxilio económico del Estado, seguramente porque no logró acoplarse a la normativa destinada a núcleos urbanos. No obstante, al tratarse de un plan pionero y sumamente interesante se ha destacado por mostrar el papel tan relevante de las Diputaciones provinciales como agentes dinamizadores a la hora de alentar a los pequeños municipios, con asentamientos de población muy dispersos, en la tarea de mejorar sus infraestructuras escolares.

${ }^{19}$ La Diputación de la vecina provincia de Guipúzcoa diseñó otro micro-plan semejante al anterior. Sus antecedentes se remontan a 1921, aunque la Comisión de Enseñanza de la Diputación no elaboraría una propuesta concreta hasta 1930. La Comisión programó la construcción de 100 escuelas en un plazo de 10 años, a razón de 10 escuelas por año, distribuidas racionalmente en los 5 distritos de la provincia. La propuesta se aprobó en 12 de diciembre de 1930, y se sustanció con la ayuda de la Caja de Ahorros de Guipúzcoa, que se comprometía a subvencionar un 10\% del coste de cada edificio, así como a adelantar los fondos precisos a un interés del $5 \%$, amortizable en 10 años. Además, a Caja colaboraría en la adquisición de material fijando un límite de 2.000 Ptas. por cada escuela. Por otro lado, la Diputación costearía el $25 \%$ de las obras, por lo que a los respectivos ayuntamientos sólo les correspondería aportar el $65 \%$ del importe total. Se levantaron 21 escuelas rurales de nueva planta, cuya construcción importó 650.000 Ptas. aproximadamente. Archivo Provincial de Guipúzcoa, JD. IT. 1457/2008
} 
lar como la económica, de los municipios se dedicaron todas las energías. Para ello se creó un Patronato de Construcciones Escolares, surgido tras la Asamblea de Alcaldes celebrada los días 10 y 11 de febrero de 1927, convocada por el Gobernador civil de la provincia, y por iniciativa del Inspector de Primera Enseñanza. La constitución de este organismo, del que formaban parte la administración central, la administración local, así como los representantes de la Caja Extremeña, fue sin duda un acierto de cara a la solución del secular problema de falta de escuelas. La Inspección de Primera Enseñanza elaboró un censo provincial, en el que se detallaban el estado de los locales-escuela y el número de niños matriculados, señalando aquellas localidades en las que era urgente construir un nuevo edificio escolar, bien por el mal estado del local, o bien por el elevado número de niños desescolarizados. Además, se realizó una especie de auditoría de las cuentas y haciendas municipales, a fin de determinar los recursos y bienes propios de que disponían, con el objetivo de comprobar qué ayuntamientos podrían obtener un crédito de la Caja Extremeña. A partir de esta información exhaustiva se elaboró un Plan de Construcciones provincial, que se remitió al Ministerio de Instrucción Pública en 1928. Se trataba de que los distintos municipios de la provincia, auxiliados económicamente por el Estado, construyesen rápida y económicamente 496 aulas escolares. En el Plan se fijaba la ubicación de las nuevas escuelas y se proponía una vía de financiación para su construcción a través de la Caja Extremeña, entidad que había mostrado previamente su compromiso con el asunto. Por último, se recurría a la participación del Estado en el coste global, estimando que para que el Plan prosperase el Estado debía aportar unos tres millones de pesetas, a modo de subvención a fondo perdido. ${ }^{20}$ Aunque el Plan no se desarrollaría tal y como se había diseñado, lo cierto fue que la colaboración entre las distintas administraciones produjo abundantes frutos, resultando las provincia cacereña una de las que más escuelas levantó dentro del territorio nacional durante esta etapa, a pesar de estar cuajada de pequeños municipios con escasos recursos económicos.

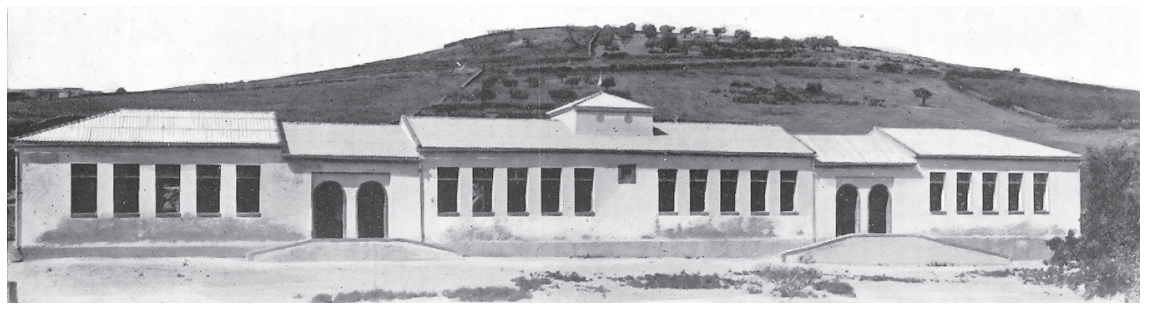

Fotografía 4. Escuelas de Talaván (Cáceres) Fuente: León Leal Ramos: La colaboración de la Caja Extremeña de Previsión Social en el fomento de las construcciones escolares (Cáceres: Imprenta Moderna, 1929).

De forma muy semejante se trabajó desde 1924 en las tres provincias aragonesas, trufadas también de pequeños núcleos de población, con bajo potencial económico pero que

${ }^{20}$ Los pormenores y desarrollo del Plan pueden consultarse en León Leal Ramos, La colaboración de la Caja Extremeña de Previsión Social en el fomento de construcciones escolares (Cáceres: Imprenta Moderna, 1929), 172. 
a través del apoyo de la Caja de Aragón sembraron su territorio de cientos de escuelas, tal y como proponía uno de sus paisanos más ilustres, D. Joaquín Costa.

\section{El crecimiento de la red escolar en las ciudades de Madrid y Barcelona}

Las ciudades de Madrid y Barcelona merecen un análisis particular por ser las dos ciudades más importantes de España, así como por el trato que les dispensó la administración central y las actitudes singulares de algunas de sus corporaciones.

El caso de la capital de España se presenta como único si se compara con el resto de grandes ciudades españolas. El hecho de que desde 1909 se reconociera por parte del Gobierno la singularidad de la capital con una dotación económica extraordinaria que recibiría por parte del Estado, ${ }^{21}$ así como el trato de favor del que gozó durante la Segunda República, distinguen a Madrid del resto de capitales, y la encumbran como la ciudad en la que más aulas se levantaron durante estos años.

La capital no contaría hasta 1911 con un plan concreto de construcciones, el redactado por el concejal socialista Joaquín Dicenta, ${ }^{22}$ que con algunos retoques fue aprobado en 1914. Preveía la edificación de nueve escuelas graduadas en tres años, aunque hasta 1918 el ayuntamiento madrileño sólo había construido dos de los colegios previstos. ${ }^{23}$ Los años siguientes estarían teñidos por el propósito de encontrar un plan que satisficiera a todos los grupos políticos, y que ayudase a resolver el grave problema escolar de la capital. ${ }^{24}$ En 1922 se acordó construir seis grupos escolares, que por circunstancias diversas demorarían su apertura a un intervalo temporal comprendido entre 1928 y 1931. Durante la II República el primer consistorio elegido tras el advenimiento republicano emprendió un ambicioso plan que cambiaría drásticamente el parque escolar de edificios públicos de la capital. Ello no fue debido sólo a la diligencia con la que actuaron los ediles del nuevo ayuntamiento madrileño,

\footnotetext{
${ }^{21}$ En el R.D. de 3 de diciembre de 1909, sobre construcción de escuelas en Madrid, se reconocía la necesidad de otorgar al ayuntamiento una amplia autonomía referida a dos cuestiones fundamentales: la construcción de escuelas -se reconocía la necesidad de construir 70 grupos escolares- y el nombramiento de maestros. El Estado se comprometía a colaborar en la financiación de los nuevos centros, incluyendo en el presupuesto un millón de pesetas durante diez años consecutivos, mientras que el concejo madrileño se responsabilizaría de redactar un Plan de Construcciones. Diversas propuestas se debatieron en el seno de las sucesivas corporaciones, sin embargo, las constantes fricciones entre ayuntamiento y gobierno por temas pedagógicos y administrativos impidieron un acuerdo inmediato.

${ }^{22}$ Según Maㅡ del Mar del Pozo, "[...] este documento es, sin duda, uno de los más importantes en la historia de la enseñanza madrileña del primer tercio del siglo XX, [....] Es la iniciativa más ambiciosa que podemos encontrar en la política educativa municipal entre 1900 y 1930 [...] el hecho de que dicho proyecto partiese de un análisis exhaustivo de la realidad, utilizando los datos estadísticos de la población escolar madrileña arrojados por el Padrón infantil de 1911 le situó en unas coordenadas de modernidad y seriedad desconocidas hasta aquel momento. Su coincidencia temporal con la discusión de los proyectos para la urbanización del Extrarradio madrileño y el hecho de que ofreciese una serie de terrenos donde podrían construirse las escuelas previstas le convirtió en el primer plan que aunaba las necesidades urbanísticas y educativas de la capital". Mํㅡㄹ del Mar del Pozo Andrés, Urbanismo y educación..., 203. ${ }^{23}$ La importancia de este plan no puede valorarse por sus resultados más inmediatos, sino por su desarrollo a largo plazo, ya que muchos de los solares contemplados como sedes de futuros centros escolares acabaron teniendo este destino en años sucesivos. Ibídem, 213.

${ }^{24}$ En el libro citado de $\mathrm{M}^{\mathrm{a}}$ - del Mar del Pozo sobre la política educativa y la expansión de la red pública escolar del ayuntamiento de Madrid en el período 1900-1931, quedan recogidas todas estas vicisitudes.
} 
en plena sintonía con las autoridades del gobierno republicano, sino también a la labor realizada por las corporaciones anteriores, así como por la política de ahorro seguida durante el septenio dictatorial por el consistorio de la capital, que legó a la nueva corporación unas arcas saneadas y con el efectivo suficiente para emprender el ambicioso y necesario Plan de Construcciones, sufragado al $50 \%$ entre el Estado y el ayuntamiento. ${ }^{25}$ Madrid fue la ciudad española en la que más aulas se construyeron durante el quinquenio republicano. No sólo superó cuantitativamente al resto de ciudades, sino que también se alzó con el primer puesto en lo que a calidad se refiere. Los grupos escolares madrileños contaron con más dependencias anejas, -bibliotecas, duchas, piscinas, cantinas, salas de reconocimiento médico-, lo que suponía un presupuesto de ejecución mucho más elevado que el del resto de centros escolares de composición semejante levantados en otras localidades. Según los datos disponibles, durante la II República se proyectaron cuarenta y seis edificios en los que se pretendía albergar a más de cuatrocientas cincuenta aulas. Se tiene constancia de la terminación de veinte edificios, con sus doscientas cuarenta y nueve aulas correspondientes.

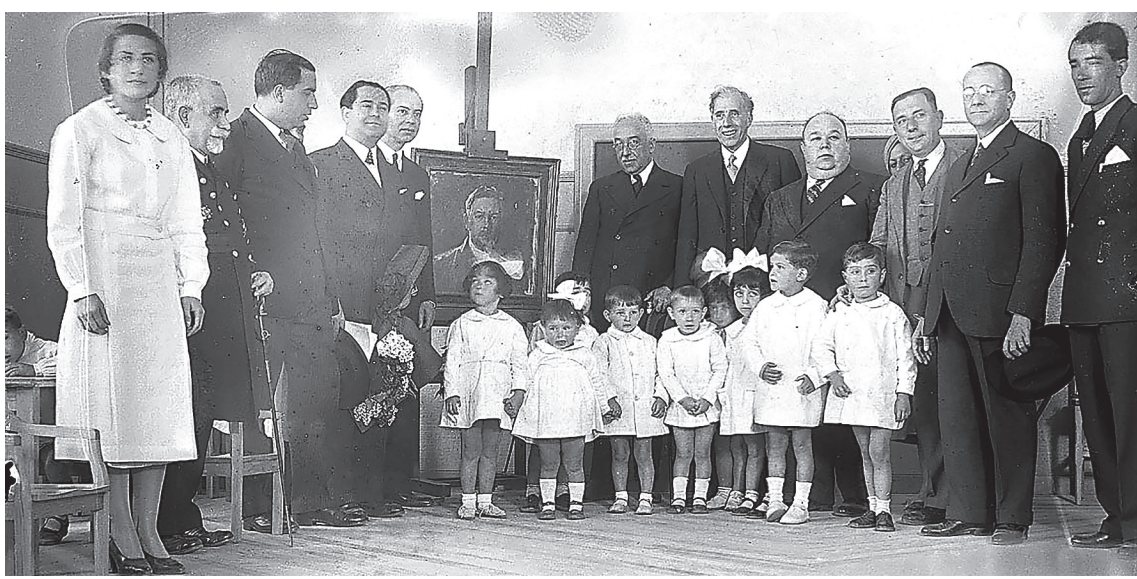

Fotografía 5. Inauguración Grupo Escolar J. Sorolla de Madrid. 1933. En la imagen aparecen el Presidente de la República, el Director General de Primera Enseñanza y el Alcalde de Madrid, entre otras personalidades. Fuente: Ministerio de Cultura y Deporte. Archivo General de la Administración. Sección de Cultura. Fondo 124. Ref. 016444.

\footnotetext{
${ }^{25}$ En la Gaceta de 14 de mayo de 1931 se apuntaba: «Dispone el Ayuntamiento de Madrid de diez millones de pesetas para emprender rápidamente la construcción de escuelas graduadas, de que tan necesitada se halla la capital, ya que existen millares de niños que no pueden recibir enseñanza primaria por carecer de escuelas, y en tales circunstancias es justo que el Estado coopere con igual cantidad que el Municipio para la realización de tan importante obra [...]. Por todo ello, el Gobierno provisional de la República decreta: Artículo único: El Estado invertirá la cantidad de diez millones de pesetas para la construcción de nuevos grupos escolares en Madrid con la cooperación del Ayuntamiento de esta capital. Dicha suma se distribuirá en cuatro anualidades: Un millón con cargo al capítulo 26, art. $1^{\circ}$ concepto único del presente presupuesto del Ministerio de Instrucción Pública, y tres millones en cada uno de los años, 1932, 1933 y 1934». En la Gaceta del 30 de mayo de 1931 se recogían ciertas disposiciones encaminadas a agilizar los trámites administrativos, a fin de que las construcciones se llevaran a cabo con la mayor celeridad posible. En las páginas de la Gaceta de 20 de septiembre de 1932 se informaba sobre la ampliación del crédito, 3 millones de pesetas más, con destino a construcciones escolares en la ciudad.
} 


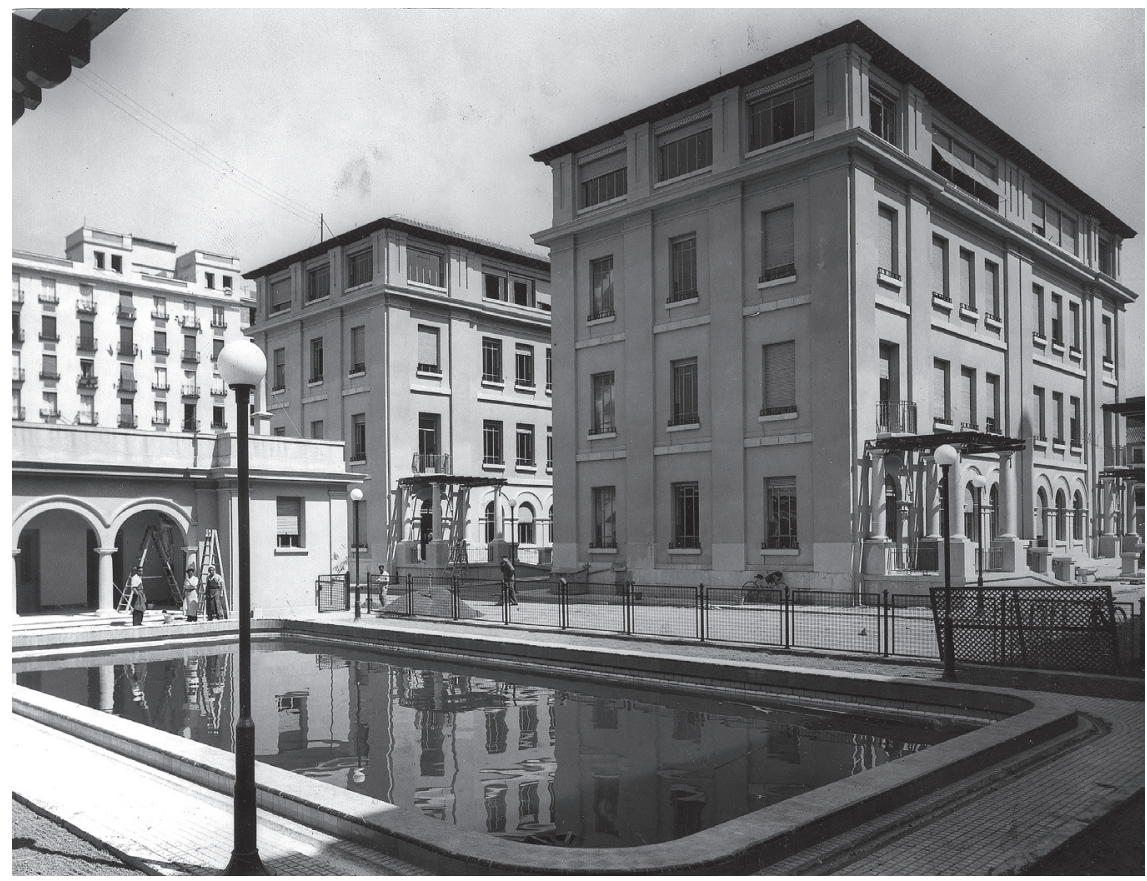

Fotografía 6. Exterior Grupo Escolar. J. Sorolla de Madrid, 1933. Fuente: Ministerio de Cultura y Deporte. Archivo General de la Administración. Sección de Obras Públicas. Fondo 82. Sobre 22.

En la segunda capital española, Barcelona, tres notas características enmarcarán la política municipal de construcciones escolares durante estos años: la primera y básica, su deseada autonomía frente al poder estatal, las fuertes demandas de escolarización derivadas del aumento de población, y la última, un gran desembolso económico, motivado tanto por la necesidad de alzar nuevos edificios como por su intención de no acudir al auxilio económico estatal, como única coartada para garantizar su independencia. Esta inversión se vería atenuada por las donaciones particulares de ricos ciudadanos, que entregarían elevadas sumas de dinero al consistorio para levantar nuevas escuelas. Es difícil aventurar una hipótesis que aclarase cuánto más habría crecido la red pública de edificios escolares en esta ciudad si las sucesivas corporaciones municipales hubiesen recurrido al auxilio económico del Estado, y no hubiesen precisado costear durante años los alquileres de numerosos locales en los que se encontraban ubicadas la mayoría de escuelas de la ciudad.

En 1908 el consistorio barcelonés se planteó la aprobación de un presupuesto extraordinario de Cultura con la intención de sufragar un plan para la construcción de cuatro complejos educativos destinados a la cultura popular, desde párvulos hasta adultos, así como una biblioteca abierta en cada barrio. El plan quedó paralizado en febrero 
de 1909, por decisión del Gobierno Civil, quien alegó extralimitaciones del consistorio barcelonés en determinados aspectos económicos, aunque la causa subyacente era el carácter laico y neutral que se quería imprimir a la enseñanza municipal, así como el excesivo grado de autonomía que el ayuntamiento se otorgaba. ${ }^{26} \mathrm{~A}$ medida que los años transcurrían y crecía la presión popular demandando centros escolares públicos, el ayuntamiento se vería abocado a afrontar con mayor empeño la resolución de la extensión de la red escolar. ${ }^{27}$ La situación de la enseñanza primaria en la ciudad era calamitosa: solo unos 15.000 niños estaban escolarizados en centros públicos, frente a unos 48.000 en privados. De los escolarizados en centros públicos, sólo unos 2.500 asistían a escuelas ubicadas en locales de propiedad municipal, el resto acudía a aulas instaladas en locales de alquiler. Lo más preocupante era que unos 20.000 niños estaban sin escolarizar. ${ }^{28}$

En 1916 se crearía la Comisión de Cultura, ${ }^{29}$ con tres objetivos: coordinar los negociados municipales relacionados con la enseñanza, planificar la expansión de la red escolar y salvaguardar la autonomía municipal frente al Estado. La Comisión, conformada por un equipo de técnicos independientes desligados de las contiendas políticas, redactaría a través de su Asesoría Técnica un Plan de Construcciones Escolares, aprobado en junio de 1917, ajustado a las necesidades de una ciudad en expansión urbanística con un fuerte crecimiento demográfico y graves carencias de infraestructuras escolares públicas.

\footnotetext{
${ }^{26}$ Tras la consulta de la bibliografía sobre el asunto parece desprenderse que tanto la intención de los concejales de aplicar en las aulas barcelonesas los principios mantenidos por la pedagogía catalana, como el deseo de utilizar su lengua, serían más fáciles de alcanzar si la labor educativa municipal permanecía al margen del Estado. Durante estos años, algunas de las escuelas públicas, creadas y gestionadas por el ayuntamiento barcelonés, fueron pioneras en la aplicación de ciertos principios de la nueva pedagogía. En ellas se impartían clases de dibujo, comercio o educación física, destacando por su singularidad la Escuela del Mary las Escuelas del Bosque, que se exhibían ante la opinión pública como ejemplos modélicos de lo que el consistorio deseaba para sus ciudadanos. Pero lo cierto era que el porcentaje de niños atendidos en estos centros era insignificante, si se comparaba con la población infantil en edad escolar. Quizá se destinaron demasiados recursos económicos al mantenimiento de estos centros y a costear el profesorado que impartía asignaturas extracurriculares. Parece que a los ediles barceloneses les interesaba más, dejar constancia de la vanguardia o singularidad de sus propuestas frente al resto del Estado español, que el conseguir la escolarización universal.

27 "Téngase en cuenta que el de los locales es el primer problema que hay que resolver para encaminar la enseñanza por derroteros más conformes con el curso actual de las ideas en todos los pueblos cultos y progresivos. Casi podría decirse que es el único [...]". Ajuntament de Barcelona, Les construccions escolars de Barcelona (Barcelona: Henrich, 1922), 152, citado por Salvador Domènech i Domènech, Els alumnes de la República. Els Grups Escolars de l'Ajuntament de Barcelona. (Barcelona: Publicaciones de l'Abadia de Montserrat, 2008), 35.

${ }^{28}$ Informe de la Comisión de Cultura, Ibídem 33-34.

${ }^{29}$ Fruto de los desvelos de la Comisión, y por ende del consistorio barcelonés, serían los edificios de los grupos escolares Baixeras y La Farigola, cuya construcción se finalizó en 1921. Inmediatamente la Comisión de Cultura y el ayuntamiento plantearon al Gobierno Central la conveniencia de que estos centros se gestionaran de forma autónoma, mediante un patronato, de manera similar a como se había acordado en los grupos escolares Cervantes y Príncipe de Asturias de Madrid. Sus demandas fueron atendidas mediante el Real Decreto de 17 de febrero de 1922, firmado por el ministro César Silió. Este Patronato aseguraba la tan ansiada autonomía organizativa para los dos centros escolares.
} 
Durante la década de los años veinte el panorama de la enseñanza primaria en la Ciudad Condal resultaba casi insostenible, a pesar de las cantidades que el ayuntamiento invertía para su funcionamiento. ${ }^{30}$ Existía, además, una diferencia acusada entre las escuelas primarias gestionadas por el municipio y las escuelas nacionales.

El Municipio de Barcelona, desde hace años, cuidó de organizar su privativa enseñanza en locales amplios, bellos e higiénicos; nuestras escuelas están situadas entre bosques, a las orillas del mar y lo mismo las colonias escolares que sostenemos en verano para fortalecer a los alumnos humildes de delicada complexión. Tenemos en casi todas las escuelas cantinas para que coman gratuitamente los niños y permanezcan todo el día bajo la protección y observación del maestro. Podemos asegurar que desde hace años la enseñanza municipal se desenvuelve en condiciones elogiadas por los más exigentes pedagogos e higienistas. No sucedía así con la enseñanza nacional del Estado, alojada generalmente en pisos de alquiler, pequeños y sombríos, sin condiciones pedagógicas y en algunos sitios sin las elementales precauciones de la higiene. No era culpa del Estado, pues corresponde a las Corporaciones municipales satisfacer y proporcionar los locales, pero los gobiernos no vigilaron con el rigor debido las deficiencias de su enseñanza, ni siquiera la orientación pedagógica de sus escuelas, saliendo multitud de niños de los centros docentes ignorando principios elementales, incluso el idioma oficial que había de facilitar la comunión espiritual de todos los españoles. ${ }^{31}$

La implantación de la Dictadura supondría, en 1924, la disolución de la Comisión y del Patronato que gestionaba las escuelas municipales más importantes de Barcelona, que no serían restaurados hasta 1930. No obstante, el Plan de Construcciones seguiría adelante y en 1929 se inaugurarían cinco grupos escolares, que serían reinaugurados, junto a otros seis, en 1931.

Durante la II República, dado que el municipio barcelonés sufría graves problemas de liquidez ocasionados en gran medida por la organización de la Exposición Internacional de 1929, las actuaciones de la Comisión se limitarían a organizar y habilitar lo mejor posible las infraestructuras, hoteles y pabellones que se habían alzado con motivo de dicha Exposición, así como a mantener vivas las aspiraciones independentistas. Durante esta etapa sólo se construyó un edificio escolar en la ciudad, sufragado mediante una donación particular.

\section{Los planes municipales de construcción de escuelas}

Como ya se ha comentado en las líneas anteriores, el Estado confiaba a los consistorios la redacción de planes particulares circunscritos a su término municipal, en los que los concejales determinarían el número de edificios escolares a levantar, su configuración y su ubicación. Si el plan era refrendado, el Estado abonaría al municipio el 50\% del coste total de las obras. Este ejemplo de descentralización administrativa daría sus frutos durante la Repú-

\footnotetext{
${ }^{30}$ Así, durante el ejercicio económico 1920-21 la institución municipal destinaría 3.800.000 Ptas. del presupuesto ordinario y 5.200.000 Ptas. del extraordinario para este capítulo, lo que equivalía aproximadamente al 6,75\% del presupuesto municipal. «El presupuesto destinado en 1919 por el ayuntamiento barcelonés a la enseñanza primaria era veinte veces superior al del ayuntamiento de Madrid», Jordi Monés: "La educación en España», en C. Atkinson y E.T. Maleska, Historia de la Educación (Barcelona: Martínez Roca, 1966), 432.

${ }^{31}$ La Vanguardia (Barcelona), 22 de mayo de 1929. Fragmento del discurso pronunciado por el Delegado de Cultura del ayuntamiento barcelonés en el acto de inauguración de cinco grupos escolares.
} 
blica en las ciudades de Madrid, Palma de Mallorca, ${ }^{32}$ Bilbao,${ }^{33}$ Zaragoza, ${ }^{34}$ Valencia, Oviedo $0^{35}$ y San Sebastián, ${ }^{36}$ y de forma particular en la provincia de Álava. Probablemente, como en el caso de Madrid, estos planes se encontrarían más o menos esbozados en los cajones de las dependencias municipales antes del advenimiento republicano, anhelando una coyuntura favorable para ver la luz o quizá esperando a que una corporación suficientemente audaz se decidiese a ponerlos en práctica. Lo cierto fue que, sin cambiar las condiciones y requisitos exigidos por el Estado a los ayuntamientos para este tipo de iniciativas, ni variar la cuantía del auxilio económico ofrecido por la administración central, estos planes comenzaron a fraguar durante la etapa republicana. Los frutos recolectados fueron diversos, oscilando entre la magnífica cosecha de Madrid, a la penuria absoluta de Valencia.

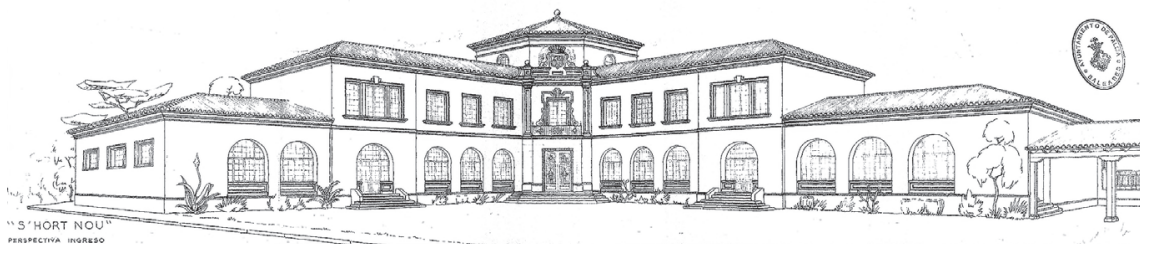

Figura 7. Plano fachada de entrada del G. Esc. Hort. Nou en Palma de Mallorca, 1932. Fuente: Ministerio de Cultura y Deporte. Archivo General de la Administración. Fondo de Educación. 32/62 Leg. 19.377.

\footnotetext{
${ }^{32}$ La ciudad insular de Palma de Mallorca resultó ser la segunda ciudad que viera aprobado por el Estado su Plan Local de Construcciones. El 9 de septiembre de 1931 su ayuntamiento había alumbrado un Plan que proponía la construcción de catorce edificios escolares ubicados tanto en la ciudad como en sus pedanías. El consistorio aportaría tanto los solares como el $50 \%$ del importe de la construcción de los edificios, y demandaba del Estado 2.150.000 de pesetas, cantidad correspondiente al importe del 50\% del presupuesto total. Transcurrió más de un año desde el acuerdo municipal hasta que el Estado refrendó el Plan. Según consta en la Gaceta de 17 diciembre de 1932, accedieron a lo demandado y concedieron los 2.150 .000 de pesetas solicitadas, distribuidas en 8 anualidades, a partir del ejercicio de 1932. Aunque no se finalizaron todos los inmuebles proyectados y el ayuntamiento tuvo serias dificultades para hacer efectivas sus aportaciones, se emprendió la construcción de la mayoría de los centros contemplados en el Plan.

${ }^{33}$ Por su parte, el ayuntamiento de Bilbao elaboró un Plan de Construcciones para su casco urbano que suponía el alzado de dos macro-grupos escolares, así como la reforma y ampliación de un tercero, presupuestado todo ello en unos diez millones de pesetas. El Gobierno accedió a ello, y le concedió una subvención de 4.000.000 Ptas. distribuidas en diez anualidades de 400.000 Ptas. Este auxilio estatal representaba el $40 \%$ del importe total de las obras. Las arcas municipales debían participar con el 60\% restante. Gaceta, 27 de diciembre de 1932. El Plan se materializó con la construcción del grupo escolar Luis Briñas, prácticamente terminado antes de la Guerra, la edificación de dos de los cinco cuerpos que componían el macro-grupo escolar Tomás Meabe, así como la terminación de las obras de reforma y ampliación del grupo Cervantes.

${ }^{34}$ El ayuntamiento de Zaragoza concertó con el Ministerio de Instrucción Pública un Plan Local de Construcciones, aportando cada administración el 50\% del total presupuestado. Con imputación a este Plan se llevaría a cabo la ejecución de obras de cuatro grupos escolares, lo que suponía la construcción de 36 nuevas aulas en la ciudad. Gaceta, 1 de mayo de 1933

${ }^{35}$ En 1934 Oviedo fue amparada por el Estado con la aprobación de su Plan Local subvencionado con 1.120.000 Ptas., equivalentes al 50\% de las obras y distribuido en cuatro anualidades. Gaceta, 27 de mayo de 1934.

${ }^{36}$ La ciudad de San Sebastián fue favorecida por el Estado con la aprobación de un Plan Local y el compromiso de un auxilio económico de 2.650.000 Ptas. distribuidas en seis anualidades, cantidad que no llegaría a hacerse efectiva por falta de tiempo antes del comienzo de la Guerra Civil. Gaceta, 23 de noviembre de 1934
} 
Como casos paradigmáticos se expone lo acontecido en la gestación del Plan valenciano, así como el Plan desarrollado por la Diputación de Álava.

La ciudad de Valencia, que al igual que tantas poblaciones españolas albergaba en su término municipal a un elevado número de niños desescolarizados, se propuso poner fin a esta situación. Como primera medida se elaboró el censo escolar de la ciudad con el objetivo de conocer las necesidades reales. A partir de estos datos se confeccionó un ambicioso Plan de Construcciones Escolares, tanto para el casco como para los arrabales. Se estimaba que tras su desarrollo podrían atenderse a unos cuarenta mil niños, cifra que representaba aproximadamente el $90 \%$ la población infantil desescolarizada o escolarizada en locales inapropiados. En el censo se contabilizaba la población infantil desde su nacimiento -ya que se consideraba que muchas madres trabajadoras debían contar con guarderías- hasta los doce años. El coste total de tan magna empresa, incluida la compra de los solares, se cifraba en sesenta millones de pesetas. ${ }^{37} \mathrm{La}$ administración central accedió a las demandas del ayuntamiento, comprometiéndose a aportar casi el 50\% del presupuesto, exactamente 26.199.134 Ptas. distribuidas en cuatro anualidades ${ }^{38}$ Este proyecto, al que podría denominarse plan integral de saneamiento escolar, el más ambicioso de los emprendidos entre las ciudades españolas, no consiguió desarrollarse. Sólo se comenzó la construcción de un grupo escolar en el Grao. Probablemente resultaba excesivo en sus metas y exigía una considerable contribución económica por parte del ayuntamiento, lo que, unido a la falta de solares municipales, complicó extremadamente su puesta en marcha. El comienzo de la Guerra malogró definitivamente su materialización.

Otro de los Planes que merecen destacarse es el confeccionado en 1932 por la Diputación alavesa, que promovería un proyecto de ámbito provincial. Se contaba con el auxilio del Estado, equivalente al $50 \%$ del presupuesto, asumiendo la institución provincial la mitad restante, contando, además, con la colaboración de los municipios interesados..$^{39}$ La Diputación solicitó a la Caja de Ahorros de Álava un préstamo de 2.445.000 Ptas., a diez años, comprometiéndose a amortizar el $10 \%$ de la obra ejecutada en cada ejercicio, así como a exigir a los municipios el pago de los intereses generados por dicha deuda, lo que les supondría un desembolso mínimo. ${ }^{40} \mathrm{El}$ Plan se ejecutó con bastante éxito, frenado sólo por ciertas disputas políticas entre los alcaldes de algunos pueblos de distinto signo político al del partido que gobernaba en la institución provincial.

\footnotetext{
${ }^{37}$ Para fijar el emplazamiento de los nuevos edificios escolares se atendió al desarrollo urbanístico de la ciudad. Para los escolares residentes en el casco urbano se proponía la construcción de 6 macro-grupos escolares con capacidad cada uno para más de dos mil niños, y otros 10 centros escolares que acogerían a más de mil alumnos cada uno. Para la población infantil huertana se proyectaban 40 escuelas rurales de dos unidades y 40 escuelas mínimas, es decir mixtas, así como dos pequeños grupos escolares con capacidad para trescientos alumnos/ as. Como extensión y complemento a la enseñanza diaria se proponía la construcción de dos pensionados, uno cerca del mar y otro próximo al bosque, que acogerían a unos quinientos alumnos. Por ellos, se apuntaba en el preámbulo del Plan, desfilaría periódicamente la población escolar. En total se planteaba el alzado de ciento un edificios escolares, en los que podrían escolarizarse a más de 39.000 alumnos. A.G.A. M.E. 32/ Leg. 19.420.

${ }^{38}$ Gaceta, 25 de febrero de 1934.

${ }^{39}$ Gaceta 17 de diciembre de 1932 y 30 de diciembre de 1932.

${ }^{40}$ Sesión de la Comisión Gestora de la Excma. Diputación Provincial de Álava, 30 de diciembre de 1932.
} 
A modo de resumen, en primer lugar, hay que señalar la excepcionalidad del Plan de Madrid, tanto por las condiciones previas a su aprobación como por la eficacia en sus resultados. En segundo lugar, se debe apuntar que los planes iniciados en 1932 en Palma de Mallorca, Bilbao y la provincia de Álava tuvieron un desarrollo aceptable, marcado siempre por los avatares de las haciendas locales, que encontraban serias dificultades para hacer efectivo su porcentaje de participación en el coste de las obras. En cuanto a los planes posteriores a 1934 su viabilidad se vio naturalmente cercenada por la Guerra.

Un caso singular que merece ser destacado es el de la ciudad de Cartagena, quizá la población que en términos relativos más escuelas construyó durante la etapa republicana, a pesar de no tener aprobado un plan local. En esta población diversas asociaciones relacionadas con la infancia promovieron el alzado de numerosas escuelas, limitándose el municipio a proporcionar el solar. No tenemos datos para explicar este modo de actuación, que produjo una cosecha excelente. Quizá el ayuntamiento delegara en los dirigentes de estas asociaciones, que suponemos desligadas de la política, para la tramitación y gestión de las ayudas estatales.

\section{Reflexiones finales. El ámbito rural versus el ámbito urbano. La colaboración de la ciudadanía con sus ayuntamientos en la construcción de escuelas}

En términos relativos se construyó con mayor intensidad en el ámbito rural. En general puede mantenerse que en las grandes ciudades las dificultades para disponer de suelo municipal o encontrar solares edificables en el emplazamiento deseado, así como el tiempo empleado en la toma de decisiones, referidas tanto la ubicación de los futuros edificios como a su composición, fueron factores que ralentizaron la construcción. Los retrasos en la toma de decisiones se derivaron en cierta medida de la disparidad de opiniones político-educativas en el seno de las corporaciones, y el tiempo extra regalado al debate demoró la llegada de la solución. Las diferencias entre los pequeños núcleos rurales y las grandes ciudades quedan patentes en los tres casos siguientes. Por ejemplo, en la capital madrileña, salvo los seis grupos escolares (unas 90 aulas), cuya construcción se aprobó en 1922, prácticamente no se edificó nada durante la etapa del Directorio Militar. Sin embargo, en la vecina provincia de Toledo se alzaron más de ciento cincuenta aulas durante los años previos el advenimiento republicano. Teniendo en cuenta que el censo de población de la provincia toledana era menor que el de la ciudad de Madrid, el contraste resulta evidente. Quizá esto pudiera explicarse tanto por las desavenencias políticas en el seno de corporación local madrileña como por la buena organización y gestión de los municipios toledanos y de otras entidades provinciales. El caso paradigmático de la provincia valenciana también resalta estas diferencias. Durante la etapa las más de trescientas aulas edificadas en esta provincia se asentaron en zonas rurales, ninguna en la capital provincial. Otro caso singular lo constituye Barcelona. Mientras que en la demarcación provincial numerosas poblaciones recurrieron a las ayudas estatales, la Ciudad Condal emprendió un camino alejado no sólo del resto de localidades provinciales, sino del habitual en el conjunto de España y no solicitó auxilio económico del Estado. 
Si se aborda la cuestión atendiendo a valores absolutos, considerando sólo como entorno urbano las capitales de provincia, durante la década de los años veinte se edificaron unas 500 aulas en las capitales de provincia, lo que representaba aproximadamente una séptima parte del total. Durante el quinquenio republicano se finalizaron en los núcleos capitalinos en torno a 700 aulas, lo que suponía una cuarta parte de las aulas alzadas. En esta última etapa, entre las ciudades de Palma de Mallorca, con unas 120 aulas, Madrid con 240 aulas, y Murcia con 56, suman más de 400, en torno al 60\% del total de las aulas levantadas en ciudades. Sin embargo, en otras capitales como Almería, Cádiz, Palencia, Valencia, Pamplona y San Sebastián no se construyó ni una sola aula. Consideradas las cifras del total de la etapa, se alzaron en torno a 1.200 aulas en el conjunto de las capitales, lo que supone, aproximadamente, un $20 \%$ del total.

Un último apunte para comentar el papel de la ciudadanía como complemento de la labor municipal en este asunto. Resulta asombroso comprobar cómo en algunas localidades cuyos consistorios habían logrado la subvención estatal para levantar su centro escolar, y después de que el inmueble se hallara completamente finalizado, las aulas no podían abrirse a los escolares por varios motivos. En algunos casos los municipios no disponían de los fondos precisos para acometer las obras de urbanización o alcantarillado que la ley les encomendaba; en otros no disponían del efectivo preciso para comprar el moblaje y ajuar escolar, incluso en ocasiones les faltaban pequeñas cantidades de efectivo para satisfacer la cuota 0 aportación que la ley señalaba como responsabilidad de los municipios, y que debía entregarse antes de que el ayuntamiento pudiera recibir el edificio. Inconvenientes todos que cercenaban la expansión de la red escolar y evidenciaban los graves problemas de liquidez que aquejaban a las arcas municipales. La organización de festivales, rifas, aportaciones vecinales y hasta bonos municipales comprados por los vecinos, fue el remedio adoptado en algunas localidades. Otras, con menos fortuna, contemplaban el magnífico edificio escolar cerrado para los alumnos, esperando a que su suerte cambiase.

A modo de resumen conviene finalmente destacar varias notas. Desde el comienzo de la década de los años veinte el Estado español se involucró cada vez más en la construcción de escuelas, pero siempre con la colaboración inexcusable e imprescindible de los municipios, instituciones responsables de iniciar los trámites para el alzado de un nuevo edificio escolar. El Estado exigió a los municipios el cumplimiento de ciertos requisitos, como facilitar el solar y una contribución económica, entre otros, sin los cuales no dispensaría sus auxilios económicos y técnicos. Las subvenciones crecieron con mayor intensidad a partir de 1926, librando el Estado cantidades a fondo perdido que rondaban el 75\% del presupuesto de obras, favoreciendo la tramitación de aquellos expedientes provenientes de corporaciones locales que demandaban ayudas de menor cuantía, y asumiendo el coste de aquellos otros que se declaraban de suma pobreza. La cuota correspondiente a la contribución municipal en general fue concertada con entidades de crédito, sobre todo con el Instituto Nacional de Previsión y sus Cajas de Ahorro.

Muchos de los proyectos de construcción aprobados por el Estado, con dotación presupuestaria, quedaron abortados o no se iniciaron por la dificultad de los consistorios para 
obtener o financiar su aportación municipal. Esta circunstancia limitó la expansión de la red y ralentizó su crecimiento, ya que las subvenciones comprometidas por el Estado desde la aprobación del proyecto quedaban retenidas sin poder ser libradas a otros ayuntamientos, que quizá se habrían mostrado más diligentes a la hora de gestionar o conseguir su aportación económica.

La disparidad en las cifras de crecimiento del número de nuevas escuelas alzadas durante estos años entre unas provincias y otras nos inclina a mantener que los auxilios económicos del Estado fueron más efectivos en aquellas provincias cuyos consistorios contaron con agentes 0 instituciones extra-municipales que les asesoraron, respaldaron 0 animaron a embarcarse en la necesaria pero difícil empresa de levantar un edificio escolar.

Las connotaciones ideológicas o políticas que pudieran haber contaminado el proceso de construcción de nuevos centros escolares parece que tuvieron poca relevancia, salvo en las grandes ciudades que decidieron emprender un plan local de construcciones, cuya redacción exigía el consenso entre las distintas fuerzas políticas que conformaban los consistorios.

Pese a todo, estos años pueden considerarse como una etapa de esplendor en el ámbito de las construcciones escolares en España, un paso necesario y decisivo en la forja de la escuela nacional, ligada al Estado, en el que los municipios desempeñaron un relevante papel.

\section{Bibliografia:}

Ajuntament de Barcelona, Les construccions escolars de Barcelona .Barcelona: Henrich, 1921. Ajuntament de Barcelona, Les construccions escolars de Barcelona. Barcelona: Henrich, 1922), citado en Els alumnes de la República. Els Grups Escolars de l'Ajuntament de Barcelona, por Salvador Domènech i Domènech. Barcelona: Publicaciones de l'Abadia de Montserrat, 2008.

Cañellas, Celia y Toran, Rosa. Política escolar de l'Ajuntament de Barcelona, 1916-1936. Barcelona: Barcanova, 1982

García Salmerón, Mํㅡㄹ del Pilar. Radiografía de las construcciones escolares públicas en España, 1922-1937. Madrid: Ministerio de Educación y Formación Profesional, 2018.

Leal Ramos, León. La colaboración de la Caja Extremeña de Previsión Social en el fomento de construcciones escolares. Cáceres: Imprenta Moderna, 1929.

Llarena, J. "Boceto de información mundial pedagógica", La Escuela Moderna, 246 (1912): 148 y 149, citado por Mํㅡㄹ del Mar del Pozo Andrés, Urbanismo y educación. Política educativa y expansión escolar en Madrid (1900-1931). Alcalá de Henares: Universidad de Alcalá, 1999.

Monés, Jordi:. "La educación en España”, en Historia de la Educación, edit. C. Atkinson y E.T. Maleska. Barcelona: Martínez Roca, 1966. 
Núñez, Clara Eugenia. La fuente de la riqueza. Educación y desarrollo económico en la España contemporánea. Madrid: Alianza Universidad, 1992.

Fontes documentais:

Gaceta, 25 de febrero de 1934.

Gaceta 17 de diciembre de 1932 y 30 de diciembre de 1932.

La Vanguardia (Barcelona), 22 de mayo de 1929.

Memoria Plan de Ordenación Escolar de Málaga, 1925. Archivo General de la Administración, Ministerio de Educación, C. 31/ C.6237.

O.M. de $28 / \mathrm{VII} / 34$.

R.D. de $23 / X I / 1920$.

R. D. de 23/XI/1920.

R.O. de 31/V/1921.

R.D. de 3/III/1922. 